DOI:

\title{
COMPARATIVE STUDY OF PHRASEMES IN RUSSIAN, SPANISH, FRENCH AND GEORGIAN LANGUAGES
}

\author{
Marine Kobeshavidze \\ Doctor in philology, Associate Professor \\ Ivane Javakhishvili Tbilisi State University \\ (Tbilisi, Georgia) \\ e-mail: mkobeshavidze@yahoo.es \\ Tsiuri Akhvlediani \\ Doctor of Pfilological Sience \\ Emeritus Professor \\ Ivane Javakhishvili Tbilisi State University \\ (Tbilisi, Georgia) \\ e-mail: akhvlediani.tsiuri@mail.ru \\ Ketevan Gabunia \\ Doctor in philology, Professor \\ Ivane Javakhishvili Tbilisi State University \\ (Tbilisi, Georgia) \\ e-mail: keti_gabunia@yahoo.com
}

\begin{abstract}
Russian, Georgian, French and the Spanish languages. Different classifications of phraseological units are analyzed in these languages. The types of the phraseological units containing numerals, birds' names and emotional units are discussed. As well, they are presented theequivalents in given languages, in one case the exact equivalent and in the other cases close analogies. The object of the analysis is a small group of equivalents and analogies of the phraseological units in Russian, Georgian, French and the Spanish languages.
\end{abstract}

Key words: phraseological units, semantic classification, functional-grammatical classification, numerals.

\section{СРАВНИТЕЛЬНОЕ ИЗУЧЕНИЕ ФРАЗЕОЛОГИЧЕСКИХ ЕДИНИЦ РУССКОГО, ИСПАНСКОГО, ФРАНЦУЗСКОГО И ГРУЗИНСКОГО ЯЗЫКОВ}

\author{
Марине Кобешавидзе \\ Доктор филологии, ассоциированный профессор \\ Тбилисский государственный университет им. Иванэ Джавахишвили \\ (Тбилиси, Грузия) \\ mkobeshavidze@yahoo.es \\ Циури Ахвледиани \\ Доктор Филологических наук, профессор эмиритус \\ Тбилисский государственный университет им. Иванэ Джавахишвили \\ (Тбилиси, Грузия) \\ akhvlediani.tsiuri@mail.ru \\ Кетеван Габуния \\ Доктор филологии, профессор \\ Тбилисский государственный университет им. Иванэ Джавахишвили \\ (Тбилиси, Грузия) \\ keti_gabunia@yahoo.com
}

\begin{abstract}
Аннотация. Статья посвящена рассмотрению испанской фразеологии с точки зрения происхождения и состава. Фоном для сравнительно-сопоставительного исследования послужили французский и грузинский языки. Названы основные группы испанской фразеологии с точки зрения происхождения. Отдельно проанализирован фраземообразующий потенциал названий птиц и гиперонима птица.
\end{abstract}

Ключевые слова: сравнительно-сопоставительный метод, фразеологическая единица, фразеокомпонент птица,

ВВЕДЕНИЕ. На сегодняшний день фразеология привлекает внимание многих исследователей как сложное и самобытное явление, которое отражающее культурную особенность нации и культуры. Фразеология является наиболее эффективным средством отображения объективной действительности, поскольку именно фразеологический состав языка играет особую роль в передаче культурно-национального самосознания народа и его идентификации. Интересно проследить и изучить, как соотносятся фразеологические единицы (ФЕ) в различных языках и культурах. В процессе сравнительно-сопоставительного ФЕ удается найти точное 
соответствие и совпадение, а иногда, особенно при переводе, приходится искать близкие или схожие по значению ФЕ.

Фразеологический состав каждого языка представляет собой многомерную комплексную систему, в которой каждый компонент обладает структурно-семантическими свойствами и отличается присущими ему характерными особенностями. В рамках данной статьи предпринята попытка рассмотреть испанские ФЕ на фоне фразеологии грузинского, русского и французского языков.

МЕТОДЫ ИССЛЕДОВАНИЯ. Данное исследование базировалось на описательно-аналитическом и компаративном методах, также были привлечены элементы лингвокультурологического метода.

ДИСКУССИЯ И РЕЗУЛЬТАТЫ ИССЛЕДОВАНИЯ. Во фразеологическом фонде любого языка отражаются национальные качества и особенности народа. Большее количество фразеологизмов различных языков появилось в прошлом и связано с бытием народа и их историей. Мы можем выделить следующие пути формирования фразеологизмов:

1. Професиональная деятельность народа: исп. a palo seco - спокойно, без спешки, без прикрас; буквально: корабль плывет не спеша, с убранными парусами с убранными парусами; исп. a todo trapo - на всех парусах, вдоволь, вволю; исп. Coger en el garlito - обмануть; caeren el garlito - попасть в сети, попасть в ловушку, франц. Tomber dans la trappe и груз. maxeSi gabma [makheshi gabma]. Все перечисленные единицы связаны с трудовой деятельностью народа и одним из основных промыслов - рыболовством.

2. Народные обычаи и история: исп. Armarse la gorda- может разгореться большой скандал; исп. Pasar la noche en blanco - провести ночь без сна, не сомкнуть глаз; франц. Passer la nuit blanche (аналог.) и груз. Ramis TeTrad gatareba [gamis tetrad gatareba]. Первый фразеологизм связан с событиями 1865 года, когда была провозглашена первая испанская республика; второй связан с рыцарским ритуалом, когда рыцарь, одетый в белое одеяние, не спал ночью перед ритуалом крещения и провозглашения рыцарем.

3. Фольклор и мифология: исп. El talónde Aquiles, франц. Le talon d'Achille, груз. Aqilevsis qusli [akilevsis qusli] - ахиллесова пята; исп. Construir castillos de arena, франц. Châteaux en Espagne, груз. Ocnebis koSkebi [otsnebis koshkebi] - возводить замки мечты; manzana de discordia, франц. Pomme de discorde, груз. ganxeTqilebis vaSli [gankhetkilebisvashli] - яблоко раздора.

4. Художественная литература: исп. Ponerle el casca bela lgato, франц. Le tout pour le tout, груз. gariskva [gariskva]- отважиться, взяться за опасное (рискованное) дело; поставить себя под удар. Выражение связано с древней басней, вариант которой встречается в «La esclava y sugalán».

5. Фонд пословиц языка: исп. hacersuagosto - поживиться (чем-либо), нажиться, нагреть руки (на чёмлибо) от пословицы Hacer el agosto y vendimia, в которой речь идет об урожае винограда и зерна, а в переносном значении получает значение «поживиться, получить прибыль».

Особую группу составляют ФЕ, вполне понятные при прямом переводе без дополнительных фоновых знаний и понимания культурных особенностей. Например: исп. Ponerse como un tomate, франц. Rougir comme une tomate, груз. pomidoriviT gawiTleba [pomidorivit gatsitleba] - покраснеть как помидор; исп. Echar ип атапо - Подать руку помоши, франц. Donner sa main, груз. Xelis waSveleba [khelistsashveleba]; исп. Todos los caminos llevana Roma, франц. Tous les chemins vont или mènent à Rome, груз. Yyvela gza romSi midis [kvelagzaromshi midis] - Все дороги ведут в Рим; исп. по tenerpelos en la lengua (букв. - языкбезволос), франц. Avoir la langue bien или trop longuе, груз. Eenas Zvali ara aqvs [enas dzvali ara aqvs] - Языкбезкостей .

Выделяется группа испанских ФЕ, не имеющих аналога в других языках, следовательно, сложных для понимания их фразеологического значения: media naranja - вторая половина, пара (букв. половина апельсина); aburrirse como una ostra - скучать (букв. скучать как устрица), pasar la noche en blanco - не спать всю ночь (букв. провести ночь в белом), por si las moscas - на всякий случай (букв. на случай, если мухи); darca la bazasa alguien - Дать om ворот поворот (букв. дать тыквы); tener mala leche - иметь плохой характер (букв. иметь плохое молоко); estar en el ajo- быть замешанным в чем-то (букв. быть в чесноке); me importa unpimiento - мне наплевать (букв. мне важен перец); salir del armario - рассказать правду о себе (букв.выйти из шкафа); a otra cosa, mariposa - Давай сменим тему (букв.к другой теме, бабочка").

Как и в других языках, в испанском языке фраземообразующим потенциалом обладают соматизмы, анимализмы, колоративы. Например, выделяется большая фразегруппа с названиями птиц: bebermenosqueunpájaro - пить как птичка; быть трезвенником; капли не брать в рот, cantarcomounpájaro - петь как соловей; заливаться соловьем; cantarcomounpajarito - пищать как птенчик, т. е. болтать лишнее. Гипероним птица обнаруживает широкий спектр сем и является самым активным с точки зрения его фраземообразующего потенциала в рассматриваемых языках: исп. Comer menos queun pajarito, франц. Manger comme une mauviette (или un moineau), груз. CitiviT kenkva - есть очень мало; клевать как птичка; исп. libre como un pájaro вольный, свободный как птица, франц. Libre comme l'air (букв.свободный как воздух), груз. CitiviT Tavisufali [chitivit tavisufali]; tímido como un pájaro, франц. Timide à l'abordée, timide comme une demoiselle (букв. робкий человек, робкий как девушка), груз. qaliSviliviT morcxvi [qalishvilivit mortskhvi] - робкий, боязливыйкакптица. Приведём и другие примеры из испанского языка: másligero que un pájaro - быстрый проворный как птица, másinocente que un pájaro - наивный,чистый, какптица.

ЗАКЛЮЧЕНИЕ. Проведённый анализ испанских ФЕ на фоне французского и грузинского языков показал, что сложность понимания ряда ФЕ обусловлена их национально-культурной спецификой. Непонимание фразеологического значение и неясность внутренней формы затрудняют описание всех сходств и различий ФЕ. Но, несмотря на существующие затруднения, сравнительно-сопоставительный анализ ФЕ интересен, поскольку 
раскрывает национальную самобытность того или иного языка и способствует эффективной межкультурной коммуникации.

\section{LIST OF REFERENCES}

Vinogradov. V.V. (1953).OsnovnieTemileksicheskikhznacheniyslova. [Main subjects of lexical meanings of a word. Linguistics questions], 21.

Vodyakha. A. A (1996). Emotivniypotentsialfrazeologicheskikhedinits. [Emotinal potential of phraseological units / Vodyakha. A. A // Vzaimodeistvieyazikovikhurovney v sferefrazeologii. [Interaction of language levels in the domain of the phraseology].

Volgograd. Peremena., 30-32.

Zhukov. V. P.(1987). Slovarfrazeologicheskikhsinonimovruskogoyazika. [Dictionary of phraseological synonyms of Russian]. M.:Russianlanguage.

KurchatkinaN.N. (1981)Frazeologia ruskogo yazika. [The phraseology of Spanish language. Moscow],8

TedoSakhokia, (1950-1955).Kartulikhatovanisitkva-tkmani [Georgian Phraseology] ).I-II-IIIt.,Tbilisi,. (in Georgian).

Frantsusko- Ruskiy frazeologicheski slovar. Moskva [French-Russian phraseological dictionary (under editing of Y. I.Retsker),

Moscow, 1963.

7. M. Moliner. Diccionario de uso del español. Segunda edición. Madrid. Gredos. 1998.

https://centroespanol.ru/blog/frazeologizmi_v_ismanskom/

Borshevich. Z. I., teacher School Volga from culture orientated organization Russian house in Valencia, Spain.COMPARATIVE

STUDY OF PHRASEMES IN RUSSIAN AND SPANISH LANGUAGES. (https://docplayer.ru/34802874-Sopostavitelnoeizuchenie-frazeologizmov-v-russkom-i-ispanskom-yazykah-comparative-study-of-phrasemes-in-russian-and-spanish-

languages.html).

\section{For citation:}

Kobeshavidze Marine, Akhvlediani Tsiuri \& Gabunia Ketevan (2019) COMPARATIVE STUDY OF PHRASEMES IN RUSSIAN, SPANISH, FRENCH AND GEORGIAN LANGUAGES // International Scientific-Pedagogical Organization of Philologists “ WEST-EAST ”(ISPOP). Scientific Journal WEST-EAST. Vol 2/1 N1 (October, 2019). pp.48-50. doi:

\section{Для цитирования:}

Кобешавидзе Марине, Ахвледиани Циури , Габуния Кетеван (2019) СРАВНИТЕЛЬНОЕ ИЗУЧЕНИЕ ФРАЗЕОЛОГИЧЕСКИХ ЕДИНИЦ РУССКОГО, ИСПАНСКОГО, ФРАНЦУЗСКОГО И ГРУЗИНСКОГО ЯЗЫКОВ // Internationa 1Scientific-Pedagogical Organization of Philologists “ WEST-EAST” (ISPOP) . Scientific Journal WEST-EAST. Vol 1/1 N1 (October, 2019). C. 48-50. doi:

Information about the author: Marine Kobeshavidze, Associate Professor, Ivane Javakhishvili Tbilisi State University, Tbilisi, Georgia

e-mail: mkobeshavidze@yahoo.es

Tsiuri Akhvlediani, Emeritus Professor, Ivane Javakhishvili Tbilisi State University, Tbilisi, Georgia

e-mail: akhvlediani.tsiuri@mail.ru

Ketevan Gabunia, Professor, Ivane Javakhishvili Tbilisi State University, Tbilisi, Georgia

e-mail: keti_gabunia@yahoo.com

Сведения об авторе: Марине Кобешавидзе, ассоциированный профессор, Тбилисский государственный университет им. Иванэ Джавахишвили, Тбилиси, Грузия

mkobeshavidze@yahoo.es

Циури Ахвледиани, профессор эмеритус,Тбилисский государственный университет им. Иванэ Джавахишвили,Тбилиси, Грузия

akhvlediani.tsiuri@mail.ru

Кетеван Габуния, профессор, Тбилисский государственный университет им. Иванэ Джавахишвили,

Тбилиси, Грузия

keti_gabunia@yahoo.com 